\title{
$O$ (des) encontro entre História e memória
}

The (dis) agreement between History and memory

CATROGA, Fernando. Memória, História e Historiografia. Rio de Janeiro: Editora FGV, 2015. 100p.

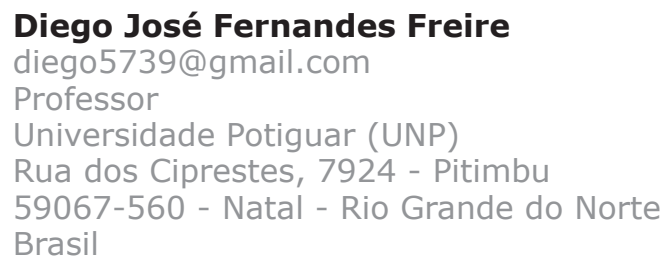

Diego José Fernandes Freire

diego5739@gmail.com

Professor

Universidade Potiguar (UNP)

Rua dos Ciprestes, 7924 - Pitimbu

59067-560 - Natal - Rio Grande do Norte

Brasil

Palavras-chave

História; Memória; Historiografia.

Keywords

History; Memory; Historiography. 
De acordo com a mitologia grega, a musa da história - Clio - teria se originado a partir da união entre Zeus e Mnemosine, deusa da memória que também deu lugar no monte Hélicon a várias outras musas gregas. Filha da memória, a história na cultura grega permaneceu durante muito tempo ligada a lembrança dos feitos humanos. Espécie de memória dos povos, a história no mundo grego guardava seus laços sanguíneos com Mnemosine e, assim, combatia o esquecimento preservando as realizações humanas. Porém, ao longo do tempo, os historiadores foram cortando o parentesco entre história e memória. Na modernidade, sobretudo no século XIX, momento em que ocorreu a institucionalização de vários saberes nas universidades, o passado mitológico da história é renegado: história não é memória, ou seja, memorialista não é historiador, bradam os metódicos franceses. Assim, a história se tornou filha ingrata da memória.

No momento em que a história almeja uma cientificidade e singularidade, acentua-se a diferenciação entre história e memória. A primeira seria fruto de um trabalho metódico, conceitual, investigativo, reflexivo, pautada em métodos ditos científicos; já a memória seria uma atividade espontânea, préreflexiva, contínua, quase natural e inerente aos indivíduos. Se a memória carregaria indelevelmente a afetividade dos sujeitos, a história traria consigo a imparcialidade, a objetividade dos fatos; uma se aproximaria do passado para revivê-lo, ao passo que a outra se distanciaria para analisa-lo. Em nome da Ciência, ergueu-se um muro para separar história e memória.

Posteriormente ao processo de disciplinarização da história, a memória continuou afastada deste saber. Os intelectuais representativos das ciências Humanas da primeira metade do século XX, como Marc Bloch, Lucien Febvre, Francois Simiand, Henri Bergson e Maurice Halbwachs, a despeito de um complexo e aprimorado debate sobre história e memória, continuaram opondo no essencial esses dois termos. Muitos historiadores da segunda metade do século passado, apesar de terem relativizado a cientificidade da história, continuaram seus antecessores na distinção entre história e memória. Embora neste momento Clio e Mnemosine tenham ensaiado um flerte familiar, espécie de flashback, a tônica continuou sendo a separação. Dois nomes de peso da historiografia francesa dão bem o tom desta distinção: Jacques Le Goff e Pierre Nora. Este último, aliás, afirmou: "memória, história: longe de sinônimos, tomamos consciência de que tudo as opõe" (NORA 1993, p. 10). ${ }^{1}$

Do exposto até agora, podemos concluir algo importante: existe uma história de longa duração da diferenciação entre história e memória, de modo que tal história é bem mais complexa do que o que aqui se apontou grosseiramente. ${ }^{2} \mathrm{O}$ livro que visamos apresentar neste texto não conta esta história, mas fornece valiosos elementos para a questionarmos. Memória, História e Historiografia, como o título sugere, procura fazer uma articulação entre as três categoriais,

\footnotetext{
${ }^{1}$ Sobre a distinção entre história e memória feita por Jacques Le Goff e com a qual certamente outros annalistas concordam ver: Le Goff (2013).

2 Para uma reconstrução resumida da oposição entre história e memória partindo do establishment francês ver: Dosse (2004, p. 169-193).
} 
mostrando suas semelhanças e diferenças. Como as diferenças são relativamente conhecidas e sustentadas pelos historiadores e teóricos das Ciências Humanas, Fernando Catroga empenha-se mais nas semelhanças que enlaçam os três termos do título do seu livro. Noções como lembrança, esquecimento, representificação e identidade aparecem em todo o livro, realizando finas e sofisticadas costuras no tecido textual da obra.

Como articular Memória, História e Historiografia? Que relações podese estabelecer entre memória e historiografia? Seria mesmo a história dos historiadores uma contra memória dos povos e dos grupos sociais? A representação do passado na memória possuiria semelhanças com a construção pretérita da historiografia? Questões como essas parecem ter ecoado na mente de Fernando Catroga, motivando-o para a escrita do livro.

Seu autor, Fernando José de Almeida Catroga, vem nos últimos anos marcando presença na historiografia brasileira. A despeito dos tradicionais diálogos entre esta historiografia e a lusitana, Fernando Catroga começou a aparecer mais efetivamente para o público brasileiro a partir dos anos 2000, quando em 2001 recebeu uma condecoração da Universidade de São Paulo por seus trabalhos sobre Portugal, os quais favoreceram a ampliação dos estudos e das iniciativas luso-brasileiras. De lá para cá, tem aqui comparecido em revistas acadêmicas e em livros, fornecendo entrevistas e tendo seus livros publicados por iniciativas brasileiras (CATROGA 2009, p. 469-487; 2005; 2009).

Fernando Catroga, professor catedrático da faculdade de letras da tradicional Universidade de Coimbra, dedica-se desde os anos 1980 ao campo da história das ideias, a partir de uma confluência com os estudos políticos e com a área de teoria da história. Temas como republicanismo, secularização da história, descristianização, positivismo, fim da história, recortados entre os séculos XVIII-XX, ocupam fortemente sua agenda de pesquisa. ${ }^{3}$

Seu livro mais recentemente publicado aqui no Brasil foi fruto da iniciativa da Editora FGV, a partir da série História da coleção de livros de bolso, coordenada pelos historiadores Marieta de Morais Ferreira e Renato Franco. Nas palavras dos editores, tal coleção é voltada para a

Produção de obras de síntese sobre os mais diversos temas das ciências humanas e sociais. Destina-se a estudantes, professores e profissionais interessados em conhecer de maneira rápida e eficaz, por meio de textos claros e acessíveis, os assuntos tratados em cada volume. Escrita por especialistas da área, a coleção FGV de Bolso reúne clareza e competência num pequeno livro (CATROGA 2015, p. 1).

É importante apontar ainda que a iniciativa de Marieta de Morais Ferreira e Renato Franco tem contribuído para a divulgação didática de questões importantes relacionadas a teoria da história e a história da historiografia, como bem atesta os livros de Jurandir Malerba (2009), Jose Carlos Reis (2010) e Luis Fernando Cerri (2011) publicados na série ora em apreço. Nesse sentido, a

\footnotetext{
${ }^{3}$ Sobre o perfil intelectual do autor, ver: http://www.uc.pt/chsc/investigadores/fjac1. Acesso em: 03 jan. 2016.
} 
Editora FGV vem contribuindo para a publicização crescente da reflexão teórica e historiográfica que vem marcando nosso momento atual. Em uma época de estudos historiográficos bastante pontuais e especializados, uma síntese escrita por alguém que conhece bem o campo no qual atua é sempre bem vinda.

Porém, ainda sobre a coleção na qual o livro Memória, História e Historiografia foi publicado, cabe uma crítica. Conforme evidenciamos na citação a seguir, a clareza e a agilidade de entendimento, objetivos caros à coleção, deixam, todavia, um pouco a desejar no livro de Fernando Catroga, tanto por questões de sua escrita, com parágrafos longos e termos rebuscados e intimamente ligados ao establishment intelectual português, como também por elementos de edição textual. Aqui, identificamos um problema que poderia ser contornado: excesso de citações em francês (contamos 20 no total, sendo muitas delas longas). Se o objetivo dos editores com a coleção é "promover uma abordagem simples e direta, acessível", por que não traduzir as citações em estrangeiro para o português, nem que fosse em rodapé? Em uma obra didática comprometida com a divulgação rápida do tema, citações em outra língua não traduzidas para o português soam como algo fora de contexto, mero preciosismo.

Deixando um pouco as questões externas de lado, o livro de Fernando Catroga divide-se em três capítulos, além de umas "palavras prévias". O capítulo inicial "recordação e esquecimento", montado a partir dos dois pares que constituem inevitavelmente a memória, traz o conceito do autor sobre o primeiro termo do título do seu livro. Nesse passo Catroga dialoga com os principais autores das Ciências Humanas que realizaram reflexões escritas sobre a memória: Henri Bergson, Maurice Halbwachs, Friedrich Nietzsche, Paul Ricoeur, Walter Benjamin, Tzvetan Todorov, Marc Augé entre outros comparecem no texto, tecendo um diálogo que mostra bem a intertextualidade do autor.

$\mathrm{Na}$ sua discussão sobre memória, Fernando Catroga parte da ideia de Umberto Eco de que "o homem é um animal histórico", isto é, os indivíduos necessitam da temporalidade para os mais diferenciados fins, sendo o tempo um elemento essencial da condição humana, tempo esse que teria como uma das formas de apreensão a memória. E isso não implica em uma naturalização da memória, dado que esta, para o autor, não é uma mera faculdade natural, ou

Um armazém inerte, onde, por ocasional e arbitrária acumulação, se recolhem os acontecimentos vividos por cada indivíduo, tal como acontece com as coisas amontoadas no sótão da casa dos avós. Bem pelo contrário. Ela é retenção afetiva e quente dos traços inscritos na tensão tridimensional do tempo - passado-presente-futuro - que permanentemente a tece (CATROGA 2015, p. 16-17).

Como se vê, o autor das palavras acima rejeita os essencialismos e as imagens clássicas sobre a memória. Não estamos aqui muito longe da ideia ricoeuriana de trabalho de memória (RICOUER 2007, p. 99-105). Esta é uma atividade, uma ação mesmo realizada pelos sujeitos e, como tal, está sujeita a todos os fatores que interferem em um trabalho qualquer: sociedade, tempo, técnicas, subjetividade etc. Sendo assim, o capítulo de abertura de Memória, 
História e Historiografia estabelece as bases teóricas sobre as quais a discussão posterior irá se desenrolar. Antes, porém, Catroga faz um rápido capítulo de transição, o qual se dedica a pontuar a noção de história do autor.

O capítulo 2, denominado "A historiografia como arsmemoriae", o menor do livro (apenas dez páginas), apresenta brevemente uma discussão conceitual sobre a historiografia, pontilhando seu nascimento e suas principais atribuições no mundo antigo greco-romano. Dialogando com Reinhart Koselleck e principalmente com François Hartog, Catroga traz à tona a historicidade antiga da história, investigando os vários significados da palavra "história" tal qual usada por Heródoto. Ao final, tem-se a seguinte conclusão:

\begin{abstract}
A historiografia nascente contava o que tinha acontecido com o fito de lembrar, à luz dos ritmos cíclicos, ou da repetição do que é característico da natureza humana, o que poderá vir a acontecer. [...] Para isso, e tal qual outras formas de bloquear o esquecimento, a historiografia era também garantia de transmissibilidade. O que dá sentido ao facto de ela ter sido qualificada como um verdadeiro testemunho contra a condenação ao Letes, isto é, como um discurso tanto memorial como alegórico ("/ux veritatis" e "vitamemoriae") (CATROGA 2015, p. 51).
\end{abstract}

A citação acima é a "deixa" do autor para começar a parte mais substancial do seu livro, contida no último capítulo, intitulado "A representificação do ausente". Após definir seu entendimento acerca das noções de memória e história, Catroga parte para o objetivo primordial de seu texto. O título do capítulo 3 fornece 136 um valioso rastro do seu pensamento: memória e historiografia não seriam tipos de "representificação do ausente"? Caçar o Outro, acertando-se com uma alteridade, não seriam objetivos comuns tanto da empresa memorialística como do empreendimento historiográfico? Memória e história não seriam grandes sínteses do passado? Para o autor, o fato de memória e história realizarem de forma diferente suas empreitadas não anularia as semelhanças entre ambas. É importante apontarmos que ele não caiu no reducionismo ingênuo de igualar história e memória. Trata-se, apenas, de não tornar as diferenças como que cinzas a apagar todas as aproximações entre os polos tradicionalmente apartados.

Segundo Fernando Catroga, quando o debate é história e memória, a discussão de boa parte dos historiadores caminha no sentido de uma radical diferenciação. É o que confirma também Beatriz Sarlo, escritora argentina formada em literatura: "o passado é sempre conflituoso. A ele se referem, em concorrência, a memória e a história, porque nem sempre a história acredita na memória, e a memória desconfia de uma reconstituição que não coloque em seu centro os direitos da lembrança" (SARLO 2007, p. 9). Disputando o passado com a memória, os historiadores tendem a opô-la a História, até mesmo no caso da História Oral, quando se defende a ideia de que os depoimentos, para virarem história, precisam ser criticados e analisados como qualquer outro documento, operação essa que, segundo alguns, violaria a reminiscência ${ }^{4}$. Para o analista

\footnotetext{
${ }^{4}$ Esta é a posição, por exemplo, de Durval Muniz de Albuquerque Junior, historiador brasileiro que na década de 1990 polemizou com a história oral, cravando radicalmente e energicamente a distinção entre história e memória (JUNIOR 2007, p. 199-211).
} 
do discurso historiográfico, faz-nos pensar o autor, tal separação precisa ser melhor pensada e avaliada:

Só um cientismo ingénuo pode aceitar a existência de uma radical separação entre a retrospectiva da memória e a retrospectiva historiográfica, tanto mais que ambas não são exclusivamente criadas pela imaginação e, ainda que por vias diferentes, aspiram ao verossímil, seja por fidelidade ou por veridição. [...] Pensando bem, as características apresentadas como típicas da memória (seleção, finalismo, presentismo, verossimilhança, representação) encontram-se, igualmente, no trabalho historiográfico, sobretudo porque, hoje, este não se restringe à busca de explicações por casualidade mecânica, elevada a deus exmachina da visão linear, acumulativa, homogénea e universalista. Afinal, a historiografia contemporânea, como saber mediato e mediado, também opera com a ideia de não continuidade do tempo e não reconhece a existência de um vazio entre o sujeito-historiador e o seu objeto (CATROGA 2015, p. 53-54).

A postura do artífice das palavras acima, além de relativizar a tradicional distinção entre história e memória, contribuiu também para pensarmos a própria história da historiografia. Se existem laços entre memória e história, se muitas vezes a segunda encontra a primeira, revestindo-se dela, a história da historiografia pode muito bem fazer o discurso da memória, e isso sem negar sua pretensão científica e seu métier institucional. Estamos longe aqui da visão segundo a qual "a história só começa no ponto onde termina a tradição, no instante em que se apaga ou se decompõe a memória social" (HALBWACHS 1990 , p. 38). História e memória podem imbricar-se, interelacionam-se, e a história da historiografia, especialmente, pode representar um terreno fértil para observar e analisar essas conexões. Na arena da historiografia, a memória pode deixar de ser adversária e virar aliada, rumo a entronização de certos enunciados.

É o próprio Catroga quem admite e discute essa possibilidade, enriquecendo ainda mais os propósitos de Memória, História e Historiografia

Também a historiografia - que nasceu sob o signo da memória - , apesar de querer falar em nome da razão, se edifica, voluntariamente ou involuntariamente, sobre silêncios e recalcamentos, como a história da história tem sobejamente demonstrado. Esta inevitabilidade aconselha a ser-se cauteloso em relação ao "discurso manifesto" dos seus textos, vigilância que deve ser redobrada quando a própria recordação é elevada a documento, isto é, ao nível arquivístico necessário para se dar objetividade ao trabalho de explicação/compreensão para onde deve subir a interpretação historiográfica (CARTOGRA 2015, p. 68).

Ao nosso ver, a principal contribuição do livro reside nessa possibilidade de pensar a história da historiografia como uma "prática de recordação disciplinar". Na ótica do autor, tal característica não anularia as outras dimensões da história da história, assim como não eliminaria outros tipos de análise. O campo da história da historiografia revela-se com uma seara rica em abordagens, de modo que o interesse de Fernando Catroga não é fechar as possibilidades a único tipo de tratamento. Ele apenas chama a atenção para uma faceta 
importante: "a escrita da história como um rito acadêmico de recordação" (CATROGA 2015, p. 56).

Diante dessa articulação entre memória, história e historiografia, como ficaria a questão da cientificidade de Clio? Ao trajar-se de memória a historiografia perderia sua áurea científica, já que este elemento é um traço fundamental para a distinção entre história e memória? O autor não aborda diretamente essas questões, já que, talvez, elas demandassem um outro capítulo ou até mesmo um outro livro. O fato é que Fernando Catroga, fazendo um texto breve porém denso e sofisticado, preferiu ficar na estrita discussão sobre os termos do título do seu livro, opção que tem seus méritos e deméritos, mas que o permitiu complexificar bastante o debate.

Por fim, cabe apontar que a discussão de Fernando Catroga lembra bastante as elucubrações de Manoel Luiz Salgado Guimarães, quando este dimensionava para a questão da "memória disciplinar" que muitas vezes a história da historiografia vinha a cimentar, a fim de legitimar suas práticas e conquistar seus postos de poder (GUIMARAES 2004). A historiografia, e mais ainda a história da historiografia, não está livre da memória, não está isenta dos mitos de origem e das invenções de tradições. Quem fará a política da memória historiográfica? Eis o questionamento que Memória, História e Historiografia nos incita.

Em tempos de institucionalização do campo, quando uma certa versão triunfa, no momento em que narrativas são criadas para serem aceitas e outras tantas para serem afastadas, é preciso suspeitar da história e dos historiadores.

138 Sendo assim, em tom de alerta, e mais uma vez aproximando história e memória, ficam as perguntas do historiador português: "Quem recorda o quê? E por quê? Que versão do passado se registra e se preserva? O que é que ficou esquecido?" (CATROGA 2015, p. 76).

\section{Referências bibliográficas}

CATROGA, Fernando. Entrevista concedida a Marieta de Morais Ferreira. Revista Brasileira de História (RBH), v. 29, n. 58, p. 469-487, 2009.

. Memória, História e Historiografia. Rio de Janeiro: Editora FGV, 2015.

. A história do mundo como tribunal do mundo. Saeculum - Revista de História, n. 21, 2009.

. Nação. Mito e Rito. Fortaleza: Museu do Ceará, 2005.

CERRI, Luis Fernando. Ensino de história e consciência histórica: implicações didáticas para uma questão contemporânea. Rio de Janeiro: Editora FGV, 2011.

DOSSE, François. A oposição História/Memória. In: DOSSE, François. História e ciências sociais. Bauru, São Paulo: Edusc, 2004, p. 169-193.

GUIMARÃES, Manoel Luiz Salgado. A cultura histórica oitocentista: a constituição de uma memória disciplinar. In: PESAVENTO, Sandra J. (org.). História 
cultural: experiências de pesquisa. Porto Alegre: Editora Universidade; UFRGS, 2003, p. 9-24.

HALBWACHS, Maurice. A memória coletiva. São Paulo: Vértice e Revista dos Tribunais, 1990.

JUNIOR, Durval Muniz de Albuquerque. Violar memórias e gestar a História: abordagem a uma problemática fecunda que torna a tarefa do historiador um parto difícil. In: ALBUQUERQUE JUNIOR, Durval Muniz de. História, a arte de inventar o passado. Bauru: Edusp, 2007, p. 199-211.

LE GOFF, Jacques. História e memória. São Paulo: Editora da Unicamp, 2013.

MALERBA, Jurandir. A história na América Latina: ensaio de crítica historiográfica. Rio de Janeiro: Editora FGV, 2009.

NORA, Pierre. Entre a história e a memória: a problemática dos lugares de memória. Revista Projeto História. Num. 10, São Paulo: Educ/PUC-SP, 1993.

REIS, Carlos Reis. O desafio historiográfico. Rio de Janeiro: Editora FGV, 2010.

RICOEUR, Paul. A memória, a história, o esquecimento. Campinas: Editora da Unicamp, 2007.

SARLO, Beatriz. Tempo passado: cultura da memória e guinada subjetiva. São Paulo: Companhia das letras; Belo Horizonte: Editora UFGM, 2007. 